\title{
Light-Powered Starter for Micro-Power Boost DC-DC Converter for CMOS Image Sensors
}

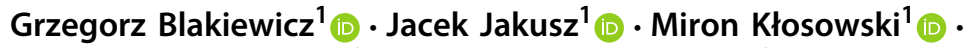 \\ Waldemar Jendernalik ${ }^{1}$ (i) $\cdot$ Stanisław Szczepański ${ }^{1}$
}

Received: 13 February 2019 / Revised: 27 June 2019 / Accepted: 29 June 2019 / Published online: 9 July 2019

(c) The Author(s) 2019

\begin{abstract}
The design of a starter for a low-voltage, micro-power boost DC-DC converter intended for powering CMOS image sensors is presented. A unique feature of the starter is extremely low current, below $1 \mathrm{nA}$, supplying its control circuit. Therefore, a high-voltage $(1.3 \mathrm{~V})$ configuration of series-connected photovoltaic diodes available in a standard CMOS process or a small external LED working in photovoltaic mode can be used as an auxiliary supply for the control circuit. With this auxiliary supply, the starter can generate a starting voltage from 1 to $2.7 \mathrm{~V}$ using 50-200 mV supply voltage. The starter was verified by simulations and measurements of a prototype chip fabricated in a standard 180-nm CMOS technology. The results of simulations and tests showed correct operation of the starter in the temperature from 0 to $50{ }^{\circ} \mathrm{C}$ and under process parameters variation.
\end{abstract}

Keywords CMOS · Low voltage $\cdot$ Low power · Boost DC-DC converter · Energy harvesting $\cdot$ Image sensor

\section{Introduction}

Energy available in the environment in the form of light, temperature gradient, electromagnetic waves or vibration can be converted into electric power [11, 13-15, 19, 20] and used to supply micro-sensors. The miniature energy harvesters can generate voltage in the range of 50-400 $\mathrm{mV}[11,13-15,19]$, which is not sufficient for proper operation of CMOS circuits. For this reason, the voltage generated by the harvesters is boosted to $1 \mathrm{~V}$ or more by step-up DC-DC converters. In recent years a number of micro-power step-up switching converters have been developed and implemented

Waldemar Jendernalik

waldemar.jendernalik@pg.edu.pl

1 Faculty of Electronics Telecommunications and Informatics, Gdańsk University of Technology, Narutowicza 11/12, 80-233 Gdańsk, Poland 
$[1-3,5,7,16-18]$. The main limitation of such converters is their inability to self-start at supply voltages as low as $50-400 \mathrm{mV}$. After starting, the converters can continue operation even at the input voltage reduced to $20 \mathrm{mV}[1,17]$, because they can generate a proper supply voltage for themselves and for other supplied circuits. The frequently applied solution to the self-start problem is to use an auxiliary starter. In the simplest form, the starter can be a battery [1], but this solution occupies large volume and has a limited life span. The starter can also be a special switching converter designed for operation at extremely low voltage. Such starter provides boosted voltage for the main converter. Unfortunately, the demand for the starter to work at very low voltage results in decreasing its power efficiency and precision of output voltage regulation. For this reason, the starter is only run for a short time to start the main converter. The starter of this type can be based on a JFET [2] or a native MOS [5] transistor with an offchip transformer. Because JFET and the native MOS transistors can operate at zero gate-source voltage, the start-up is possible even at $20 \mathrm{mV}$. Because of the need for the off-chip transformer and because JFET is not compatible with CMOS technology, these approaches are limited in application. Another solutions $[4,12,18]$ use an LC oscillator based on very-low-threshold-voltage MOS transistors and a Dickson charge pump to generate a sufficiently high start-up voltage.

In the known starter solutions, a voltage source was used as a power source and the main research was focused on reduction of the self-start voltage. In this study, a different approach is applied. Instead of a low-voltage source, a current source with very low current, below $1 \mathrm{nA}$ and voltage of 1.1-1.3 V, is used to power the starter control circuit. Such approach is particularly suitable for sensors exposed to light, because the required current source can be realized as a set of photovoltaic diodes connected in series, which are available in a standard CMOS process [10]. Therefore, the proposed starter can be integrated with a CMOS image sensor.

\section{Principle of Operation}

\subsection{Basic Assumptions and Working Conditions}

The concept diagram of the proposed starter is shown in Fig. 1. In this starter, a single period of power conversion consists of two cycles. During the first one, the equivalent input capacitance $C_{\mathrm{IN}}$ is charged by means of the auxiliary current source $I_{\text {aux }}$. In the next cycle, the transistor $\mathrm{M}_{1}$ is switched off, by quick discharge of $C_{\mathrm{IN}}$, to generate a boosted voltage at the drain. To initiate operation of the starter, the gate-source voltage $V_{\mathrm{GS} 1}$ must be increased to

$$
V_{\mathrm{GS} 1} \cong V_{\mathrm{th}}+\frac{1}{R_{\mathrm{ON} 1}} \frac{1}{K_{\mathrm{PN}}(W / L)_{1}}
$$

where $V_{\text {th }},(W / L)_{1}, K_{\mathrm{PN}}$ and $R_{\mathrm{ON} 1}$ are the threshold voltage, the aspect ratio, the transconductance parameter and the required switch-on resistance of $\mathrm{M}_{1}$, respectively. 


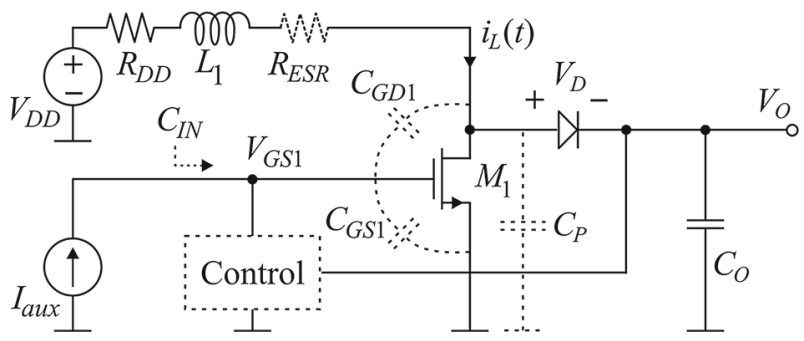

Fig. 1 Schematic diagram showing the principle of operation of the starter

Due to a low supply voltage $\left(V_{\mathrm{DD}}<V_{\mathrm{GS} 1}-V_{\mathrm{T}}\right)$, the MOS transistor model [9] for the triode region is used in (1). When $V_{\mathrm{GS} 1}$ increases to the value (1), the current $i_{\mathrm{L}}(t)$ flowing through the inductor $L_{1}$ reaches its maximum value equal to

$$
I_{\max }=\frac{V_{\mathrm{DD}}}{R_{\mathrm{ON} 1}+R_{\mathrm{ESR}}+R_{\mathrm{DD}}}
$$

where $R_{\mathrm{ESR}}$ and $R_{\mathrm{DD}}$ are the inductor equivalent series resistance and the supply source internal resistance. The current accumulates in the inductor the energy $E_{L}$

$$
E_{L}=\frac{1}{2} L_{1} I_{\max }^{2}=\frac{L_{1} V_{\mathrm{DD}}^{2}}{2\left(R_{\mathrm{ON} 1}+R_{\mathrm{ESR}}+R_{\mathrm{DD}}\right)^{2}}
$$

When the switch $\mathrm{M}_{1}$ opens, the energy (3) is released through the diode and is mainly consumed to charge the output capacitor $C_{\mathrm{O}}$ and the parasitic capacitance $C_{\mathrm{P}}$. Part of this energy is dissipated in the diode, due to the voltage drop $V_{\mathrm{D}}$, and is also dissipated in $M_{1}$ because of a limited switching-off time and other parasitic effects. Therefore, the energy balance is

$$
E_{\mathrm{L}}=E_{\mathrm{O}}+E_{\mathrm{P}}+E_{\mathrm{D}}+E_{\mathrm{M} 1}=\frac{1}{2} C_{\mathrm{O}} V_{\mathrm{O}}^{2}+\frac{1}{2} C_{\mathrm{P}} V_{\mathrm{off}}^{2}+E_{\mathrm{D}}+E_{\mathrm{M} 1}
$$

where $V_{\mathrm{O}}$ is the output voltage, $V_{\text {off }}$ is the amplitude of the drain voltage pulse after switching off the transistor, and $E_{\mathrm{D}}$ and $E_{\mathrm{M} 1}$ are the energy dissipated in the diode and in the transistor, respectively. Typical waveforms of the inductor current $i_{\mathrm{L}}(t)$, the voltage drop $v_{\mathrm{D}}(t)$ across the diode and the voltage $V_{\text {off }}(t)$ at the drain of $\mathrm{M}_{1}$ are depicted in Fig. 2.

Figure 2 shows that while the diode is conducting current, the voltage drop $v_{\mathrm{D}}(t)$ on it and as a consequence voltage on the inductor are almost constant, and therefore, the inductor current $i_{\mathrm{L}}(t)$ decreases linearly in time. Taking this into account, the energy $E_{\mathrm{D}}$ can be estimated as

$$
E_{\mathrm{D}}=\int_{0}^{\Delta t} v_{\mathrm{D}} i_{\mathrm{L}} \mathrm{d} t \cong \frac{V_{\mathrm{D}} I_{\max }}{2} \Delta t \cong \frac{V_{\mathrm{D}} I_{\text {max }}}{2} \frac{L_{1} I_{\text {max }}}{V_{\text {off }}}
$$

where $\Delta t$ is the duration of the drain voltage pulse $V_{\mathrm{off}}(t)$ and $V_{\mathrm{D}}$ is the maximum voltage drop across the diode. The energy $E_{\mathrm{M} 1}$ is difficult to calculate, because it 


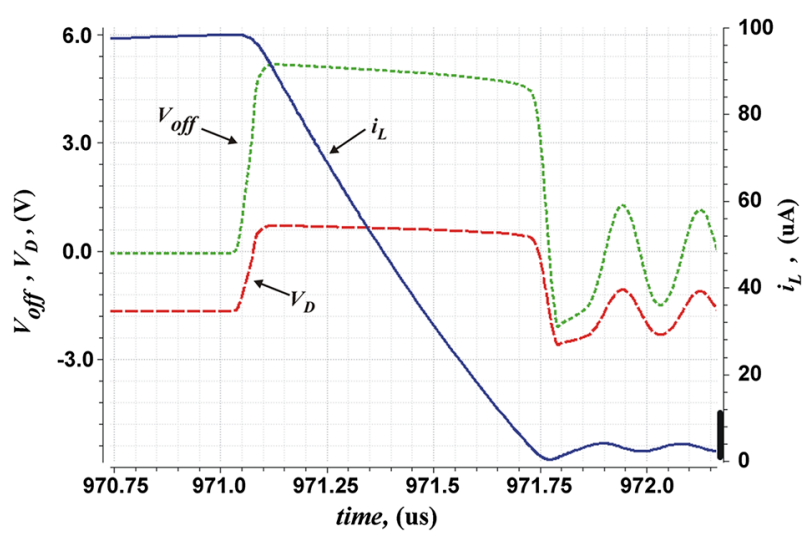

Fig. 2 Waveforms of the inductor current $i_{\mathrm{L}}(t)$, voltage $V_{\text {off }}(t)$ at $\mathrm{M}_{1}$ drain and voltage drop $v_{\mathrm{D}}(t)$ across the diode after switching off $\mathrm{M}_{1}$ transistor

depends on many factors such as $\mathrm{M}_{1}$ switching-off time, the ratio of $V_{\mathrm{GS} 1}$ to $V_{\text {th }}$ before $\mathrm{M}_{1}$ switching-off, $R_{\mathrm{ON} 1}$, amplitude of $V_{\mathrm{off}}(t)$, oscillations. For this reason, the efficiency factor $\eta$ is introduced which models the energy loss in the transistor. Using this factor, the loss can be expressed as $E_{\mathrm{M} 1}=(1-\eta) E_{\mathrm{L}}$, where the value of $\eta$ is determined during preliminary simulations based on the energy stored in the inductor and the energy dissipated in the transistor in a single switching cycle, as explained in Sect. 3.2. Based on (3)-(5), and taking into account that $V_{\text {off }}=V_{\mathrm{O}}+V_{\mathrm{D}}$, the required inductor current can be estimated as

$$
I_{\max } \cong \sqrt{\frac{\left(V_{\mathrm{D}}+V_{\mathrm{O}}\right)\left[C_{\mathrm{O}} V_{\mathrm{O}}^{2}+C_{\mathrm{P}}\left(V_{\mathrm{D}}+V_{\mathrm{O}}\right)^{2}\right]}{L_{1}\left[\eta V_{\mathrm{O}}-(1-\eta) V_{\mathrm{D}}\right]}}
$$

It is assumed that the auxiliary current $I_{\text {aux }}$ is used only to initiate the first switch-on of $\mathrm{M}_{1}$, and the next cycles of charging $C_{\mathrm{IN}}$ are supplied using the output voltage $V_{\mathrm{O}}$. This assumption allows for a reliable start when the starter control circuit is powered from a source with very low current efficiency and accumulated energy, such as a set of serial-connected photovoltaic diodes integrated on a chip. However, the prerequisite for this mode of operation is to meet the following two conditions. First, the maximum inductor current (2) should be greater than (6) to generate the $V_{\mathrm{O}}$ high enough (greater than (1)) to sustain the operation of the starter. Second, the switching period should be greater than the time constant $L_{1} /\left(R_{\mathrm{ON} 1}+R_{\mathrm{ESR}}+R_{\mathrm{DD}}\right)$; otherwise, the $i_{\mathrm{L}}(t)$ will not reach the required value (6). Thus, the minimum energy for the starter initialization is

$$
E_{\mathrm{start}}=\frac{1}{2} C_{\mathrm{IN}} V_{\mathrm{GS} 1}^{2}
$$

where $V_{\mathrm{GS} 1}$ is such that the current (2) is greater than (6), and $C_{\mathrm{IN}} \cong C_{\mathrm{GS} 1}+C_{\mathrm{GD} 1}$ because the parasitic capacitances of the transistor $\mathrm{M}_{1}$ are dominant. 


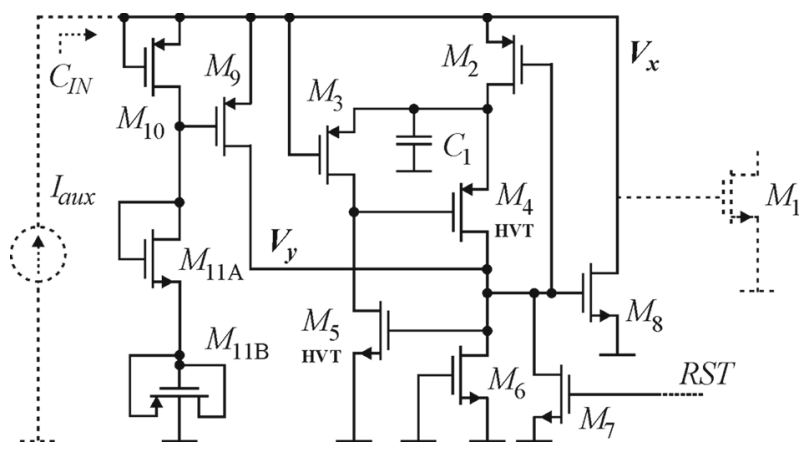

Fig. 3 Relaxation oscillator as a control circuit (HVT devices are 1.8-V transistors with high threshold voltage)

\subsection{Relaxation Oscillator}

The starter in Fig. 1 needs a control circuit that periodically switches the $\mathrm{M}_{1}$. To minimize the starting energy, the control circuit should consume as small power as possible. A circuit proposal with such characteristics is shown in Fig. 3. In this configuration, the equivalent capacitance $C_{\mathrm{IN}}$ serves as a temporary voltage source supplying the control circuit. Therefore, in ideal conditions, to discharge $C_{\mathrm{IN}}$, no additional energy is required in addition to the energy previously stored in it.

The reuse of energy stored in $C_{\mathrm{IN}}$ for the discharging is mainly limited by the static power consumed by the control circuit, because the energy dissipated exactly at the switching transition is desirable since it accelerates the discharging of $C_{\mathrm{IN}}$.

When the circuit is idle, the static power is dissipated as a result of the leakage currents flowing through all the transistors connected between the gate of $\mathrm{M}_{1}$ and ground. This power can be minimized by using long channel transistors $(L>1 \mu \mathrm{m})$ and transistors M4 and M5 with high threshold voltage (HVT) having small leakage current. As a result, the total static current in the proposed circuit is $190 \mathrm{pA}$ at room temperature. The circuit in Fig. 3 together with $C_{\mathrm{IN}}$ and $I_{\text {aux }}$ acts as a relaxation oscillator. The transistors $\mathrm{M}_{3}, \mathrm{M}_{5}$ and $\mathrm{M}_{4}, \mathrm{M}_{6}$ form two cross-coupled inverters functioning as an RS latch. Each inverter is composed of $\mathrm{M}_{4}\left(\mathrm{M}_{5}\right)$ transistor loaded by a very large resistance resulting from $\mathrm{M}_{3}\left(\mathrm{M}_{6}\right)$ leakage current. The transistors sizes are chosen in such a way that $\mathrm{M}_{4}$ and $\mathrm{M}_{5}$ are always switched off when the latch is idle. Two transistors $\mathrm{M}_{9}$ and $\mathrm{M}_{7}$ are used to set, respectively, high or low voltage levels at the latch output $V_{y}$. The circuit composed of $\mathrm{M}_{10}, \mathrm{M}_{11 \mathrm{~A}}, \mathrm{M}_{11 \mathrm{~B}}$ defines the threshold level $V_{\mathrm{TH} 1}$ of the voltage $V_{x}$ at which the latch is triggered. Although the threshold $V_{\mathrm{TH} 1}$ is dependent on temperature and process variation, this solution was chosen because of the very low bias current, which in this case is of utmost important. The influence of the threshold $V_{\mathrm{TH} 1}$ variation on the operation of the starter will be discussed in Sect. 4. When the $V_{x}$ reaches the threshold level $V_{\mathrm{TH} 1}$, the drain current of $\mathrm{M}_{9}$ increases and sets the latch output to high. At the same time, $\mathrm{M}_{8}$ switches on and discharges $C_{\mathrm{IN}}$. It should be noted that without $\mathrm{M}_{2}$ and $\mathrm{C}_{1}$, the capacitance $C_{\mathrm{IN}}$ could not be discharged completely. The incomplete discharge occurs, because after switching on $\mathrm{M}_{4}$ (assum- 


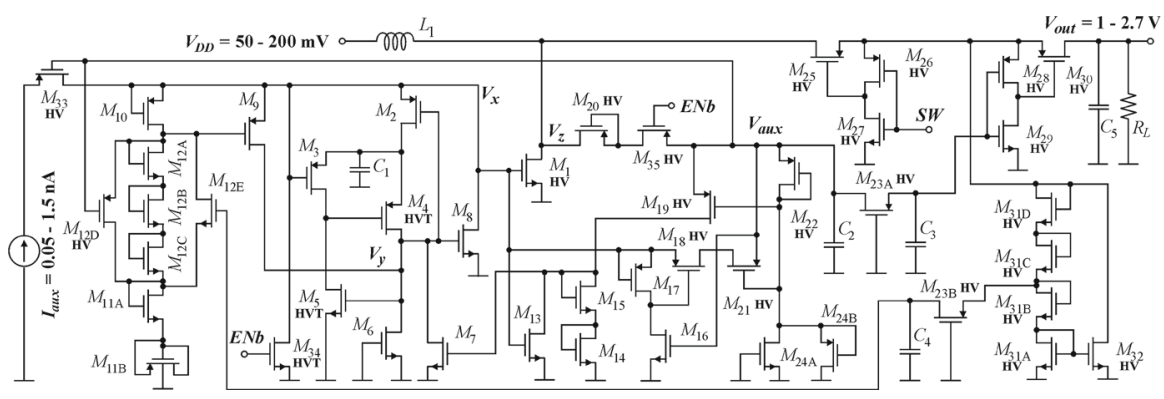

Fig. 4 Complete schematic diagram of the proposed starter (HV are high-voltage 5-V transistors, HVT are 1.8-V transistors with high threshold voltage)

ing that $\mathrm{M}_{2}$ is shorted) the transistor $\mathrm{M}_{8}$ forms the diode-connected configuration. As a result, the final minimal voltage $V_{y}$ can only reach the $\mathrm{M}_{8}$ threshold voltage and therefore cannot be zeroed. As a consequence, the boosting level of the output voltage is significantly reduced. To avoid such a situation, the temporary voltage source in the form of $\mathrm{C}_{1}$ is used to provide the gate-source voltage for $\mathrm{M}_{8}$ high enough to discharge $C_{\mathrm{IN}}$ completely. Therefore, $\mathrm{M}_{2}$ plays two roles: It disconnects $\mathrm{C}_{1}$ from $V_{x}$ during the discharge transition, preventing $\mathrm{C}_{1}$ from complete discharging, and it recharges $\mathrm{C}_{1}$ to full voltage $V_{x}$ after discharging $C_{\mathrm{IN}}$. The relaxation oscillator needs periodic resetting of the latch after each state change, which is done by means of $\mathrm{M}_{7}$ and the signal $R S T$.

\section{Starter for a Boost DC-DC Converter}

\subsection{Starter Realization}

The proposed starter is only intended for generating the start-up voltage sufficient for a main boost converter. Therefore, after the converter initialization the starter is disabled. The complete schematic of the starter is depicted in Fig. 4. The circuit consists of the following functional blocks: the relaxation oscillator $\left(\mathrm{M}_{2}-\mathrm{M}_{12}, \mathrm{C}_{1}\right)$, the feedback supplying circuit $\left(\mathrm{C}_{2}, \mathrm{M}_{16}-\mathrm{M}_{18}, \mathrm{M}_{21}, \mathrm{M}_{22}, \mathrm{M}_{24}\right)$, the MOS rectifiers $\left(\mathrm{M}_{20}, \mathrm{M}_{25}\right)$, the voltage limiter $\left(\mathrm{M}_{31 \mathrm{~A}}-\mathrm{M}_{31 \mathrm{D}}, \mathrm{M}_{32}\right)$ and the disabling circuit $\left(\mathrm{M}_{34}\right.$, $\mathrm{M}_{35}$ ) which switches off the starter after the boost converter initialization. To limit the number of off-chip components, the starter shares $\mathrm{L}_{1}$ with the boost converter.

When the relaxation oscillator switches off $\mathrm{M}_{1}$ for the first time, a positive pulse voltage $V_{z}$ at the drain is generated. This pulse switches on the rectifiers $\mathrm{M}_{20}$ and $\mathrm{M}_{25}$ (initially the signal $S W$ is low). During the first switching, $\mathrm{M}_{30}$ is turned off because its gate is connected to source by $\mathrm{M}_{28} . \mathrm{M}_{30}$ is switched on after the delay resulting from charging $\mathrm{C}_{3}$ by means of $\mathrm{M}_{23 \mathrm{~A}}$. Therefore, the large capacitor $\mathrm{C}_{5}$ and the other supplied circuits are disconnected during this period. As a result, most of the energy accumulated in the inductor $L_{1}$ is released through $\mathrm{M}_{20}$ and $\mathrm{M}_{35}$ to the capacitor $\mathrm{C}_{2}$. Since $C_{2}$ has relatively small capacitance, the voltage across $C_{2}$ quickly rises above the latch threshold. From this moment, the starter is able to power itself using $\mathrm{C}_{2}$ as 
an auxiliary voltage source for $I_{\text {aux }}$ generation. The transistors $\mathrm{M}_{21}, \mathrm{M}_{22}, \mathrm{M}_{24}$ form a current source which takes over the role of the source $I_{\text {aux }} \cdot \mathrm{M}_{16}-\mathrm{M}_{18}$ are used to prevent a feedforward flow of the $I_{\text {aux }}$ during the first switching of $\mathrm{M}_{1}$. In this period, $\mathrm{M}_{18}$ is switched off, because its gate is connected to the source by the leakage current of $M_{17}$. When the starter switches to the auxiliary source $C_{2}, M_{18}$ is turned on by $\mathrm{M}_{16}$, which connects the gate of $\mathrm{M}_{18}$ to ground. At the same time, the source $I_{\text {aux }}$ is disconnected, by turning off $\mathrm{M}_{33}$, to prevent energy losses.

For a proper operation, the relaxation oscillator needs cyclic resetting. This task is accomplished by $\mathrm{M}_{7}, \mathrm{M}_{13}-\mathrm{M}_{15}$ and $\mathrm{M}_{19}$. When the voltage $V_{\text {aux }}$ on $\mathrm{C}_{2}$ reaches a sufficient level, $\mathrm{M}_{7}$ switches on and resets the latch output $V_{y}$ to zero. From this moment, the voltage $V_{x}$ may increase and $C_{\mathrm{IN}}$ may be charged again. $\mathrm{M}_{13}$ is used to disable $\mathrm{M}_{7}$ and cancel the resetting of the latch to enable next switching of the relaxation oscillator.

To minimize the starting energy, the threshold level of the latch is modulated. During the first switching on of $\mathrm{M}_{1}$, the threshold voltage of the latch is set to the minimum, defined by $\mathrm{M}_{11 \mathrm{~A}}, \mathrm{M}_{11 \mathrm{~B}}$, since $\mathrm{M}_{12 \mathrm{D}}$ is switched on $\left(V_{\mathrm{aux}}=0\right)$. This voltage is such that the starter generates energy to charge the capacitor $C_{2}$ to the required minimal level (1). Such small energy is not sufficient to charge a much larger capacitor $\mathrm{C}_{5}$ to the level required by a boost converter. Therefore, during next cycles of oscillation the latch threshold voltage is increased, by switching off $\mathrm{M}_{12 \mathrm{D}}$, to the level defined by $\mathrm{M}_{11 \mathrm{~A}}, \mathrm{M}_{11 \mathrm{~B}}$ and $\mathrm{M}_{12 \mathrm{~A}}-\mathrm{M}_{12 \mathrm{C}}$.

During the initial oscillations, it is not possible to precisely control voltages $V_{\text {aux }}$ and $V_{\text {out }}$ which may result in exceeding permissible voltage limits. To protect the circuit from damage by too high voltage, the voltage limiter composed of $\mathrm{M}_{31}-\mathrm{M}_{32}$ is applied. When the amplitude of $V_{z}$ pulse exceeds the permissible value, $\mathrm{M}_{12 \mathrm{E}}$ and $\mathrm{M}_{32}$ are switched on to reduce the latch threshold voltage, $V_{\text {aux }}$, and $V_{\text {out }}$.

After several cycles of oscillation, when $V_{\text {out }}$ reaches the required start-up voltage for a proper operation of the boost converter, the starter is disabled by pulling the signal ENB to high. At the same time, the transistor $\mathrm{M}_{25}$ changes its role from the rectifier to a switch controlled by the pulse-width-modulated signal SW, which is generated by a circuit controlling the boost converter.

The exemplary waveforms illustrating the starter operation are presented in Fig. 5. The bottom waveform shows voltage $V_{x}$ across $C_{\mathrm{IN}}$. During the initialization period, the voltage gradually increases until it reaches, at about $420 \mu \mathrm{s}$, the latch threshold level of $0.81 \mathrm{~V}$. After the first switching, the threshold is increased to about 1.2 V. From this moment, relaxation oscillations begin. As shown in the top and middle plots, the first switching charges $\mathrm{C}_{2}$ to about $V_{\text {aux }}=2.55 \mathrm{~V}$ and $\mathrm{C}_{5}$ to $V_{\text {out }}=20 \mathrm{mV}$. After about $1.7 \mathrm{~ms}$, both voltages reach the final values $V_{\text {aux }}=2.3 \mathrm{~V}$ and $V_{\text {out }}=2 \mathrm{~V}$. It should also be noted that after $1.7 \mathrm{~ms}$, the latch threshold voltage is reduced to about $1 \mathrm{~V}$ to limit the output voltage. In most working conditions, the first switching is sufficient to charge $\mathrm{C}_{2}$ to a high enough level, but if this action fails, the switching will resume automatically. 


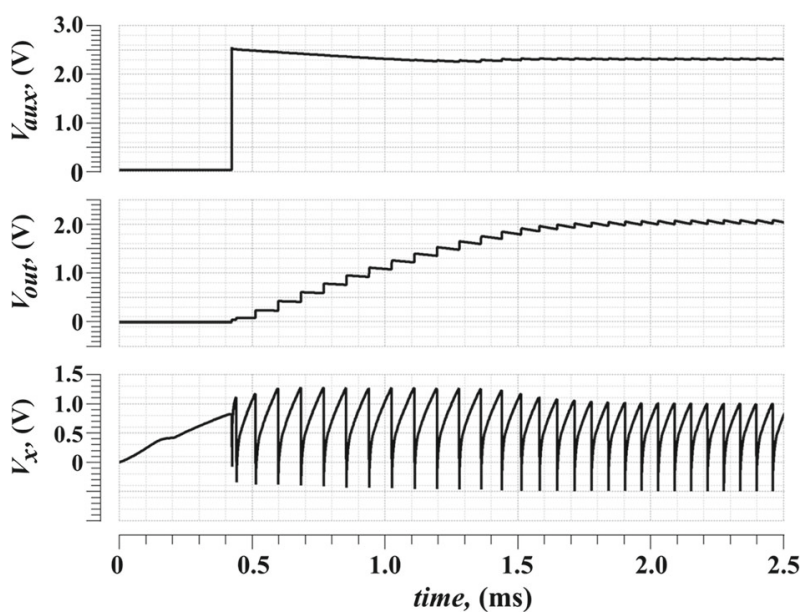

Fig. 5 Exemplary waveforms of the starter voltages: $V_{\text {aux }}, V_{\text {out }}$ and $V_{x}$

\subsection{Design Procedure}

The design procedure is explained based on two variants of the starter: (1) with the minimal starting energy and (2) with the lowest start-up voltage. The starter is designed for a boost converter that requires the start-up voltage $V_{\text {out }} \geq 1 \mathrm{~V}$. The AMS 180-nm standard CMOS technology was selected for both variants of the project. To make the preliminary calculations, the following parameters were assumed: $V_{\mathrm{DD}}=50 \mathrm{mV}$, $R_{\mathrm{DD}}=5 \Omega, L_{1}=800 \mu \mathrm{H}, R_{\mathrm{ESR}}=0.35 \Omega$. The remaining parameters were estimated as follows. The capacitance $\mathrm{C}_{5}=10 \mathrm{nF}$ was selected to achieve $V_{\text {out }}$ voltage ripple less than $20 \mathrm{mV}_{\mathrm{pp}}$. The $\mathrm{C}_{2}$ equal to $120 \mathrm{pF}$ was chosen to obtain $V_{\text {aux }}$ voltage ripple less than $100 \mathrm{mV}$ which guarantees correct operation of the relaxation oscillator. The capacitance $\mathrm{C}_{1}=0.6 \mathrm{pF}$ is ten times larger than the input capacitance of $\mathrm{M}_{8}$, to keep the $\mathrm{M}_{8}$ gate-source voltage high enough to discharge $C_{\mathrm{IN}}$ completely. The efficiency factor $\eta=1-E_{M 1} / E_{L}=0.7$ was determined based on the energy dissipated in the transistor $E_{M 1}$ and the energy stored in the inductor $E_{L}$, where both energies were calculated by simulation for a single switching period. The determined maximum voltage drop on the rectifier $\mathrm{M}_{25}$ was $V_{\mathrm{D}}=0.9 \mathrm{~V}$.

As explained in the previous section, two threshold levels are used in the latch. The first threshold level $V_{\mathrm{TH} 1}$ should guarantee generation of enough energy to charge $C_{2}$ to voltage greater than (1), while the second threshold level $V_{\mathrm{TH} 2}$ should be sufficient to charge $C_{2}+C_{5}$ and provide enough power for the load $R_{L}$. After the first switching, the required gate-source voltage (1) is generated by the feedback supplying circuit $\left(\mathrm{M}_{16}-\mathrm{M}_{18}, \mathrm{M}_{21}, \mathrm{M}_{22}, \mathrm{M}_{24}\right)$, which needs at least $50 \mathrm{mV}$ voltage drop for proper operation. Therefore, the minimal initial voltage (1) must be greater by this value. The first variant of the starter, with the minimal starting energy, was design using (1), (2), (6) and finding dimensions $W_{1}$ and $L_{1}$ of the transistor $\mathrm{M}_{1}$ for which the energy (7) is minimal. It is assumed that $C_{\mathrm{IN}} \cong W_{1} L_{1} C_{o x}+C_{1}, C_{P}=2 W_{1} C_{o v}+$ $C_{x}$ where $C_{o x}$ is the capacitance per unit area of $\mathrm{M}_{1}$ gate oxide, $C_{o v}$ is the overlap 
Table 1 Parameters of the starter in Fig. 4

\begin{tabular}{lll}
\hline Device: $\mu \mathrm{m} / \mu \mathrm{m}$ & Device: $\mu \mathrm{m} / \mu \mathrm{m}$ & Device: $\mu \mathrm{m} / \mu \mathrm{m}$ \\
\hline $\mathrm{M}_{3}: 10 / 2$ & $\mathrm{M}_{17}: 10 / 0.18$ & $\mathrm{M}_{24 \mathrm{~B}}: 10 / 1$ \\
$\mathrm{M}_{4}: 5 / 2$ & $\mathrm{M}_{18}: 1 / 10$ & $\mathrm{M}_{25}: 50 / 0.5$ \\
$\mathrm{M}_{6}: 5 / 2$ & $\mathrm{M}_{19}: 5 / 2$ & $\mathrm{M}_{26}: 10 / 1$ \\
$\mathrm{M}_{7}: 2 / 5$ & $\mathrm{M}_{20}: 2 / 0.5$ & $\mathrm{M}_{27}: 5 / 1$ \\
$\mathrm{M}_{8}: 10 / 2$ & $\mathrm{M}_{21}: 20 / 1$ & $\mathrm{M}_{30}: 50 / 1$ \\
$\mathrm{M}_{10}: 12 / 2$ & $\mathrm{M}_{22}: 2 / 10$ & $\mathrm{M}_{30 \mathrm{~A}-\mathrm{D}}: 5 / 1$ \\
$\mathrm{M}_{11 \mathrm{~B}}: 3 / 2$ & $\mathrm{M}_{23 \mathrm{~A}}: 1 / 10$ & $\mathrm{M}_{32}: 500 / 0.7$ \\
$\mathrm{M}_{12 \mathrm{D}}: 1 / 4$ & $\mathrm{M}_{23 \mathrm{~B}}: 1 / 10$ & $\mathrm{C}_{1}=0.6 \mathrm{pF}$ \\
$\mathrm{M}_{16}: 2 / 10$ & $\mathrm{M}_{24 \mathrm{~A}}: 10 / 1$ & $\mathrm{C}_{3,4}=1 \mathrm{pf}$ \\
Other transistors: $2 / 2$ & $\mathrm{M}_{1}: 500 / 0.7$ for min start-up voltage & $\mathrm{M}_{1}: 1500 / 0.7$ for min start-up energy \\
\hline
\end{tabular}

capacitance per channel unit width, and $C_{x}$ is the capacitance resulting from $\mathrm{M}_{20}, \mathrm{M}_{25}$ $\left(C_{x} \cong 0.4 \mathrm{pF}\right)$. In this case, for the worst technology corner $\left(V_{\mathrm{T}} \cong 520 \mathrm{mV}, K_{\mathrm{PN}} \cong 100\right.$ $\mu \mathrm{A} / \mathrm{V}^{2}, C_{o x} \cong 2.5 \mathrm{fF} / \mu \mathrm{m}^{2}, C_{o v} \cong 0.5 \mathrm{fF} / \mu \mathrm{m}^{2}$ ) the required first threshold voltage is $V_{\mathrm{TH} 1} \cong 800 \mathrm{mV}$, and the transistor dimensions are $W_{1} \cong 500 \mu \mathrm{m}$ and $L_{1}=0.7 \mu \mathrm{m}$.

The second variant of the starter, with the lowest start-up voltage, was calculated using the same set of equations, but finding the transistor dimensions for which the gate-source voltage (1) is minimal. In this case, the optimal parameters are as follows: $V_{\mathrm{TH} 1} \cong 650 \mathrm{mV}, W_{1} \cong 1500 \mu \mathrm{m}$ and $L_{1}=0.7 \mu \mathrm{m}$.

The second threshold level $V_{\mathrm{TH} 2}$ depends on the required charging rate of $\mathrm{C}_{5}$ and the load resistance $\mathrm{R}_{\mathrm{L}}$. The greater the $V_{\mathrm{TH} 2}$ is, the faster the output voltage $V_{\text {out }}$ reaches its final value. Since the maximum value of $V_{\mathrm{TH} 2}$ is limited by $V_{\text {aux }}$, which is in the range of 1.6-2.4 V, with a small margin of safety it was assumed that $V_{\mathrm{TH} 2}$ $=1.5 V_{\mathrm{TH} 1}$. The effects of $V_{\mathrm{TH} 1}$ and $V_{\mathrm{TH} 2}$ changes due to temperature and process variations are discussed in Sect. 4.1. The complete set of circuit parameters is listed in Table 1

\section{Analysis of Working Conditions and Technology Nonidealities}

\subsection{Technology Corners and Temperature Variation}

Due to the use of leakage currents for biasing of devices, the influence of technology corners and temperature variation on the starter operation is examined. Five corners are specified for AMS (austriamicrosystems AG) 180-nm CMOS technology: TM, WP, WS, WO and WZ, meaning, respectively, the typical mean values, worst-case power, worst-case speed, worst-case one and worst-case zero.

For a proper operation of the starter, both transistors $\mathrm{M}_{4}$ and $\mathrm{M}_{5}$ must always be switched off when the latch is idle. To meet such a condition, $\mathrm{M}_{3}$ leakage current must always be greater than $\mathbf{M}_{5}$ leakage current. Similarly, the sum of $\mathbf{M}_{4}$ and $\mathrm{M}_{9}$ leakages should be greater than the sum of $\mathrm{M}_{6}$ and $\mathrm{M}_{7}$ leakages. Such conditions are 
satisfied by using HVT transistors $\mathrm{M}_{4}$ and $\mathrm{M}_{5}$ and proper sizing of the other devices. It is also required that the threshold voltages $V_{\mathrm{TH} 1}$ and $V_{\mathrm{TH} 2}$ of the latch were as constant as possible and greater than (1). These voltages, in the circuit in Fig. 4, can be approximated as

$$
\begin{gathered}
V_{\mathrm{TH} 1}=V_{\mathrm{DS} 11 \mathrm{~A}}+V_{\mathrm{SB} 11 \mathrm{~B}}+V_{\mathrm{th} 9} \\
V_{\mathrm{TH} 2}=V_{\mathrm{DS} 11 \mathrm{~A}}+V_{\mathrm{SB} 11 \mathrm{~B}}+V_{\mathrm{DS} 12 \mathrm{~A}}+V_{\mathrm{DS} 12 \mathrm{~B}}+V_{\mathrm{DS} 12 \mathrm{C}}+V_{\mathrm{th} 9}
\end{gathered}
$$

where $V_{\mathrm{DS} 11 \mathrm{~A}}, V_{\mathrm{DS} 12 \mathrm{~A}}-V_{\mathrm{DS} 12 \mathrm{C}}$, are the drain-source voltages of $\mathrm{M}_{11 \mathrm{~A}}$ and $\mathrm{M}_{12 \mathrm{~A}}-\mathrm{M}_{12 \mathrm{C}}$, respectively, $V_{\mathrm{SB} 11 \mathrm{~B}}$ is the source-body voltage of $\mathrm{M}_{11 \mathrm{~B}}$, whereas $V_{\text {th9 }}$ is the threshold voltage of $\mathrm{M}_{9}$. The transistors $\mathrm{M}_{11 \mathrm{~A}}$ and $\mathrm{M}_{11 \mathrm{~B}}\left(\mathrm{M}_{12 \mathrm{~A}}-\mathrm{M}_{12 \mathrm{C}}\right)$ are biased by the leakage current of the $\mathrm{p}$-channel transistor $\mathrm{M}_{10}$, which can be approximated by [9]

$$
I_{\text {leak } 10} \cong\left(\frac{W}{L}\right)_{10} I_{\mathrm{O} 10}\left(\frac{T}{T_{0}}\right)^{2} e^{-\frac{V_{\text {th10 }}}{n V_{T}}}
$$

where $I_{\mathrm{O} 10}$ and $n$ are technology parameters, $V_{\mathrm{T}}$ is the thermal voltage, and $T_{\mathrm{O}}$ is a reference temperature. On the other hand, the drain-source voltage of each transistor $\mathrm{M}_{11 \mathrm{~A}}, \mathrm{M}_{12 \mathrm{~A}}-\mathrm{M}_{12 \mathrm{C}}$ working in the subthreshold region is

$$
V_{\mathrm{DSN}} \cong V_{\mathrm{th} N}+n V_{\mathrm{T}} \ln \left(I_{\text {leak } 10}\right)-n V_{\mathrm{T}} \ln \left[\left(\frac{W}{L}\right)_{\mathrm{N}} I_{\mathrm{ON}}\left(\frac{T}{T_{\mathrm{O}}}\right)^{2}\right]
$$

Taking into account the leakage current (9), the drain-source voltage can be determined as

$$
V_{\mathrm{DSN}} \cong V_{\mathrm{th} N}-V_{\mathrm{th} 10}+n V_{\mathrm{T}} \ln \left[\left(\frac{W}{L}\right)_{10} I_{\mathrm{O} 10} /\left\{\left(\frac{W}{L}\right)_{\mathrm{N}} I_{\mathrm{ON}}\right\}\right]
$$

The expressions (11), (8a) and (8b) show that the latch thresholds depend mainly on the difference between the threshold voltages $V_{\mathrm{th} N}$ and $V_{\mathrm{th} 10}$ of the n-channel $\left(\mathrm{M}_{11 \mathrm{~A}}\right.$, $\left.\mathrm{M}_{12 \mathrm{~A}}-\mathrm{M}_{12 \mathrm{C}}\right)$ and p-channel $\left(\mathrm{M}_{10}\right)$ transistors. Because the temperature coefficients of both voltages $V_{\text {thN }}$ and $V_{\text {th10 }}$ are similar, the change of voltage (11) with temperature is reduced.

Figure 6 shows the simulations results of $V_{\mathrm{TH} 1}$ and $V_{\mathrm{TH} 2}$ changes with temperature and corners. For TM corner, $V_{\mathrm{TH} 1}$ varies from $920 \mathrm{mV}$ to $860 \mathrm{mV}$ for the temperature from 0 to $70{ }^{\circ} \mathrm{C}$. The total variation of $V_{\mathrm{TH} 1}$, including all the corners and temperature change, is 820-946 mV. As explained in Sect. 3.1, the first threshold level $V_{\mathrm{TH} 1}$ is used during the start-up of the relaxation oscillator, when it is powered from the photovoltaic diodes. The starter is designed to be powered from the photovoltaic diodes in the configuration described in [10] or a small external LED working in photovoltaic mode. In both cases, the generated voltage is in the range of 1.1-1.3 V, which guarantees proper start-up of the relaxation oscillator. 


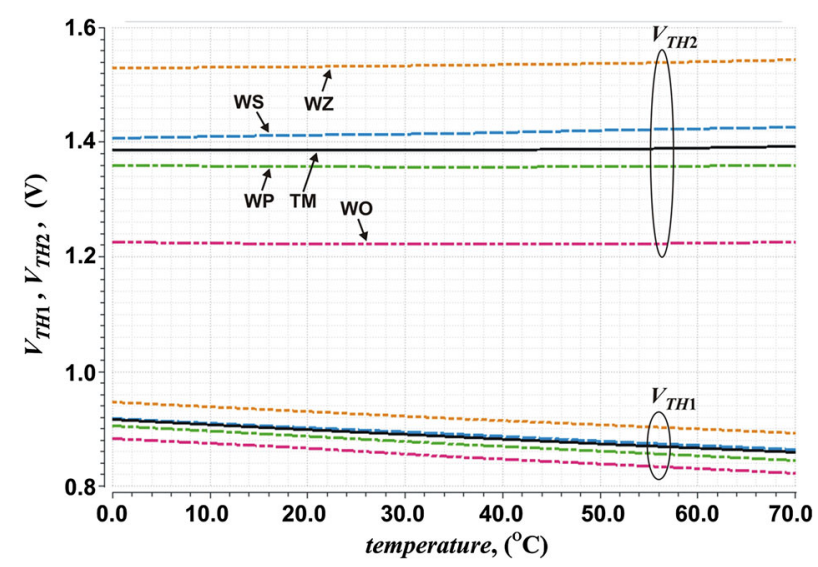

Fig. $6 V_{\mathrm{TH} 1}$ and $V_{\mathrm{TH} 2}$ variation with temperature and corners
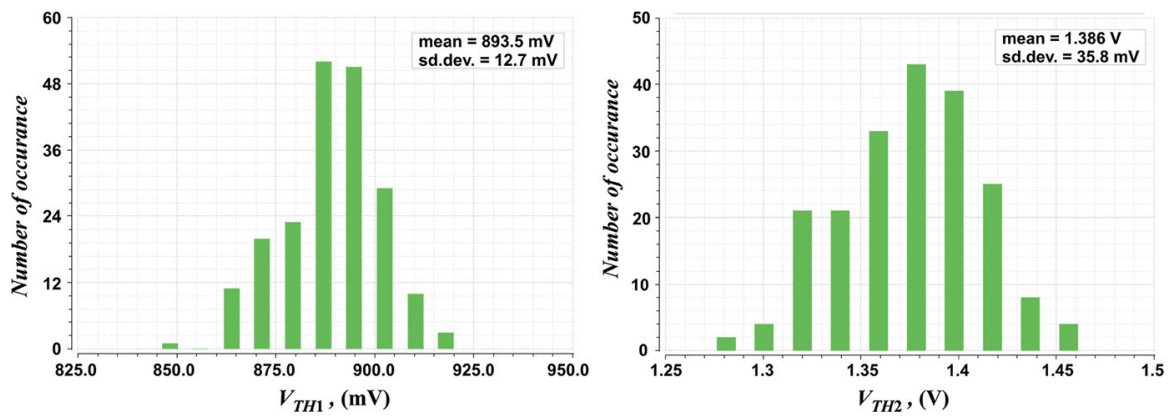

Fig. 7 Monte Carlo simulation results of $V_{\mathrm{TH} 1}$ and $V_{\mathrm{TH} 2}$ for TM corner at $27^{\circ} \mathrm{C}$

Figure 6 shows that under the same conditions, the second threshold voltage $V_{\mathrm{TH} 2}$ changes from 1.386 to $1.394 \mathrm{~V}$ for TM corner and from 1.2 to $1.544 \mathrm{~V}$ for all the corners and temperature range $0-70{ }^{\circ} \mathrm{C}$. The $V_{\mathrm{TH} 2}$ is used to reduce the charging time of the capacitor $\mathrm{C}_{5}$, and therefore, its relatively large variation has less impact on the starter operation. Because after starting, the oscillator is powered from the auxiliary source $V_{\text {aux }}$ higher than $1.6 \mathrm{~V}$, the operation of the oscillator is sustained regardless of changes in $V_{\mathrm{TH} 2}$. The changes in $V_{\mathrm{TH} 1}$ and $V_{\mathrm{TH} 2}$ caused by mismatch of the transistors dimensions and variation of technology parameters achieved with 200 runs of the Monte Carlo simulations are illustrated in Fig. 7 for TM corner and temperature $27{ }^{\circ} \mathrm{C}$. The complete set of simulation results for all the corners and temperatures 0 , 27, $70{ }^{\circ} \mathrm{C}$ is presented in Table 2. Both threshold voltages are within the range of acceptable values $\left(0.8 \mathrm{~V}<V_{\mathrm{TH} 1}<1.1 \mathrm{~V}\right.$ and $\left.V_{\mathrm{TH} 2}<1.6 \mathrm{~V}\right)$.

\subsection{Output Voltage Variation}

As the proposed starter is to be used only for a short initialization period to start a boost converter, a simple mechanism for controlling the output voltage $V_{\text {out }}$ is applied. 
Table 2 Summary of the Monte Carlo simulation of $V_{\mathrm{TH} 1}$ and $V_{\mathrm{TH} 2}$

\begin{tabular}{|c|c|c|c|c|c|c|}
\hline \multirow[t]{2}{*}{ Corner } & \multicolumn{3}{|l|}{$V_{\mathrm{TH} 1}(\mathrm{mV})$} & \multicolumn{3}{|l|}{$V_{\mathrm{TH} 2}(\mathrm{~V})$} \\
\hline & $0{ }^{\circ} \mathrm{C}$ & $27^{\circ} \mathrm{C}$ & $70^{\circ} \mathrm{C}$ & $0{ }^{\circ} \mathrm{C}$ & $27^{\circ} \mathrm{C}$ & $70^{\circ} \mathrm{C}$ \\
\hline $\mathrm{TM}$ & $\begin{array}{l}M=916.6 \\
\mathrm{SD}=11.8\end{array}$ & $\begin{array}{l}M=893.5 \\
\mathrm{SD}=12.7\end{array}$ & $\begin{array}{l}M=859.6 \\
\mathrm{SD}=13.1\end{array}$ & $\begin{array}{l}M=1.385 \\
\mathrm{SD}= \\
0.0345\end{array}$ & $\begin{array}{c}M=1.386 \\
\mathrm{SD}= \\
0.0358\end{array}$ & $\begin{array}{c}M=1.392 \\
\mathrm{SD}= \\
0.0362\end{array}$ \\
\hline WP & $\begin{array}{l}M=906.0 \\
\mathrm{SD}=12.1\end{array}$ & $\begin{array}{l}M=881.5 \\
\mathrm{SD}=12.8\end{array}$ & $\begin{array}{l}M=845.0 \\
\mathrm{SD}=13.2\end{array}$ & $\begin{array}{l}M=1.360 \\
\mathrm{SD}=0.035\end{array}$ & $\begin{array}{l}M=1.357 \\
\mathrm{SD}= \\
0.0367\end{array}$ & $\begin{array}{c}M=1.359 \\
\mathrm{SD}= \\
0.0352\end{array}$ \\
\hline WS & $\begin{array}{l}M=918.8 \\
\mathrm{SD}=11.5\end{array}$ & $\begin{array}{l}M=897.8 \\
\mathrm{SD}=11.7\end{array}$ & $\begin{array}{l}M=865.0 \\
\mathrm{SD}=11.9\end{array}$ & $\begin{array}{l}M=1.406 \\
\mathrm{SD}= \\
0.0335\end{array}$ & $\begin{array}{l}M=1.413 \\
\mathrm{SD}= \\
0.0343\end{array}$ & $\begin{array}{c}M=1.426 \\
\mathrm{SD}= \\
0.0348\end{array}$ \\
\hline WO & $\begin{array}{l}M=882.7 \\
\mathrm{SD}=11.6\end{array}$ & $\begin{array}{l}M=859.3 \\
\mathrm{SD}=11.7\end{array}$ & $\begin{array}{l}M=823.6 \\
\mathrm{SD}=13.2\end{array}$ & $\begin{array}{l}M=1.225 \\
\mathrm{SD}=0.034\end{array}$ & $\begin{array}{l}M=1.223 \\
\mathrm{SD}=0.036\end{array}$ & $\begin{array}{c}M=1.226 \\
\mathrm{SD}= \\
0.0368\end{array}$ \\
\hline WZ & $\begin{array}{l}M=947.5 \\
\mathrm{SD}=11.8\end{array}$ & $\begin{array}{l}M=925.3 \\
\mathrm{SD}=12.3\end{array}$ & $\begin{array}{l}M=893.9 \\
\mathrm{SD}=13.6\end{array}$ & $\begin{array}{l}M=1.528 \\
\mathrm{SD}=0.036\end{array}$ & $\begin{array}{c}M=1.532 \\
\mathrm{SD}= \\
0.0365\end{array}$ & $\begin{array}{c}M=1.541 \\
\mathrm{SD}= \\
0.0372\end{array}$ \\
\hline
\end{tabular}

$M$ mean value, $S D$ standard deviation

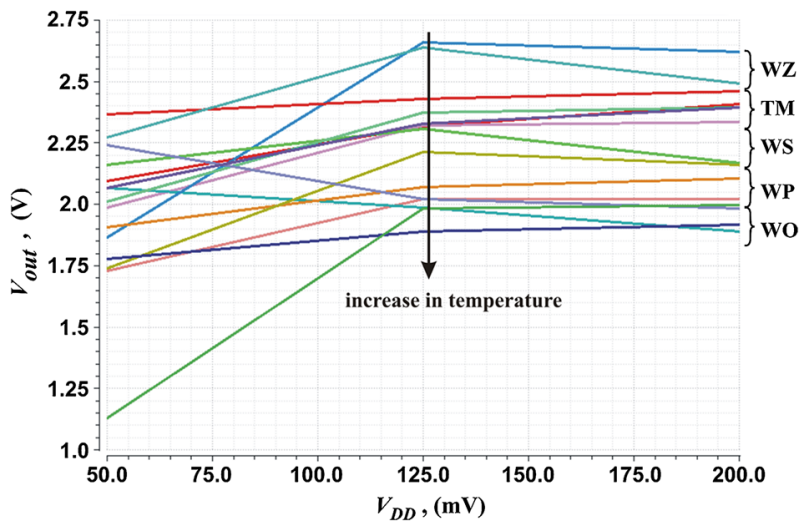

Fig. $8 V_{\text {out }}$ as a function of $V_{\mathrm{DD}}$ for all combinations of temperatures $0{ }^{\circ} \mathrm{C}, 27{ }^{\circ} \mathrm{C}$ and $70{ }^{\circ} \mathrm{C}$ and corners TM, WP, WS, WO and WZ

For relatively small supply voltages $V_{\mathrm{DD}}<50 \mathrm{mV}$, the output voltage is unregulated, whereas for higher voltages the output is limited by the circuit composed of $\mathrm{M}_{31 \mathrm{~A}}-\mathrm{M}_{31 \mathrm{D}}, \mathrm{M}_{32}$ and $\mathrm{M}_{12 \mathrm{E}}$. The characteristics of the output voltage are shown in Fig. 8. The curves shown refer to all combinations of the five corners TM, WP, WS, WO and $\mathrm{WZ}$ and three temperatures $0{ }^{\circ} \mathrm{C}, 27^{\circ} \mathrm{C}$ and $70^{\circ} \mathrm{C}$. The output voltage $V_{\text {out }}$ ranges from 1.12 to $2.7 \mathrm{~V}$ for $V_{\mathrm{DD}}$ from 50 to $200 \mathrm{mV}$, which guarantees a reliable start of the converter.

To determine the $V_{\text {out }}$ changes caused by devices mismatch and process variation, 200 iterations of Monte Carlo simulations were performed. The results for TM corner and $V_{\mathrm{DD}}=50 \mathrm{mV}$ are illustrated in Fig. 9 for $0{ }^{\circ} \mathrm{C}$ and $70^{\circ} \mathrm{C}$, whereas a summary of 

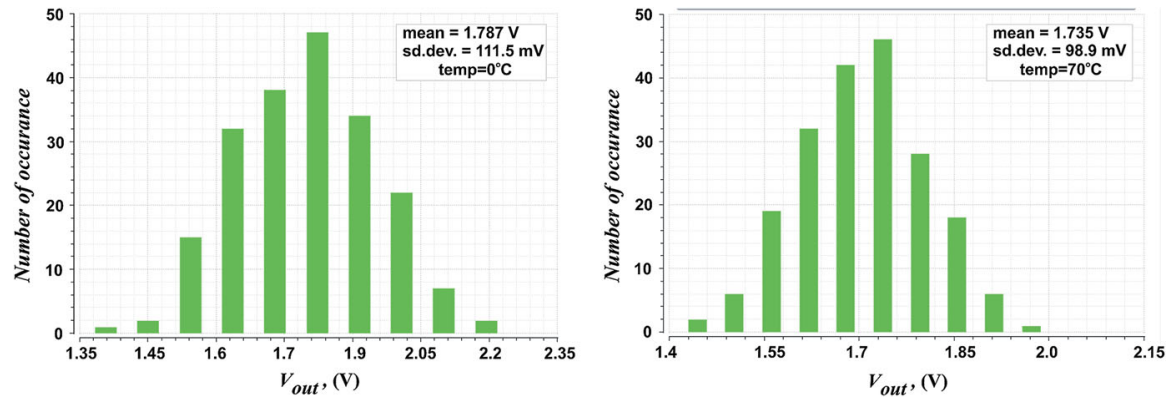

Fig. 9 Monte Carlo simulation results of $V_{\text {out }}$ for TM corner at $0{ }^{\circ} \mathrm{C}$ and $70{ }^{\circ} \mathrm{C}$

Table 3 Summary of the Monte Carlo simulation of $V_{\text {out }}$ at $V_{\mathrm{DD}}=50 \mathrm{mV}$

\begin{tabular}{llll}
\hline Corner & \multicolumn{2}{l}{$V_{\text {out }}(\mathrm{V})$} & \\
\cline { 2 - 4 } & $0^{\circ} \mathrm{C}$ & $27^{\circ} \mathrm{C}$ & $70^{\circ} \mathrm{C}$ \\
\hline $\mathrm{TM}$ & $M=1.787$ & $M=1.772$ & $M=1.735$ \\
& $\mathrm{SD}=0.112$ & $\mathrm{SD}=0.105$ & $\mathrm{SD}=0.0989$ \\
WP & $M=1.772$ & $M=1.755$ & $M=1.715$ \\
& $\mathrm{SD}=0.109$ & $\mathrm{SD}=0.1$ & $\mathrm{SD}=0.099$ \\
WS & $M=1.12$ & $M=1.113$ & $M=1.08$ \\
& $\mathrm{SD}=0.117$ & $\mathrm{SD}=0.105$ & $\mathrm{SD}=0.1$ \\
WO & $M=2.05$ & $M=2.025$ & $M=1.98$ \\
& $\mathrm{SD}=0.128$ & $\mathrm{SD}=0.121$ & $\mathrm{SD}=0.115$ \\
WZ & $M=2.35$ & $M=2.37$ & $M=1.89$ \\
& $\mathrm{SD}=0.113$ & $\mathrm{SD}=0.105$ & $\mathrm{SD}=0.099$ \\
\hline
\end{tabular}

$M$ mean value, $S D$ standard deviation

the results for all the corners at $0{ }^{\circ} \mathrm{C}, 27{ }^{\circ} \mathrm{C}$ and $50{ }^{\circ} \mathrm{C}$ is given in Table 3 . The output voltage varies from 1.08 to $2.37 \mathrm{~V}$, and therefore, a reliable start of the converter is possible. The main reasons for the output voltage changes are the changes in the threshold voltages $V_{\mathrm{TH} 1}, V_{\mathrm{TH} 2}$ and the switch-on resistance of $\mathrm{M}_{1}\left(R_{\mathrm{ON} 1}\right.$ in (1)). The $V_{\text {out }}$ variation could be reduced by means of negative feedback; however, in such a case it would not be possible to achieve very low auxiliary current $I_{\text {aux }}<1 \mathrm{nA}$ due to the complexity of the feedback circuit.

\subsection{Auxiliary Current Variation}

The auxiliary current $I_{\text {aux }}$ is mainly used for charging the input equivalent capacitance $C_{\mathrm{IN}}$. Only a relatively small fraction of this current is consumed by the leakage current of the control circuit. The plots of the minimum $I_{\text {aux }}$ necessary to initiate the starter as a function of temperature and corners are presented in Fig. 10. For the $V_{\text {DD }}$ equal to $50 \mathrm{mV}$ and all the corners, the current is below $1 \mathrm{nA}$ if temperature is lower than $57{ }^{\circ} \mathrm{C}$, while for TM corner and room temperature the current is $190 \mathrm{pA}$. Such a low 


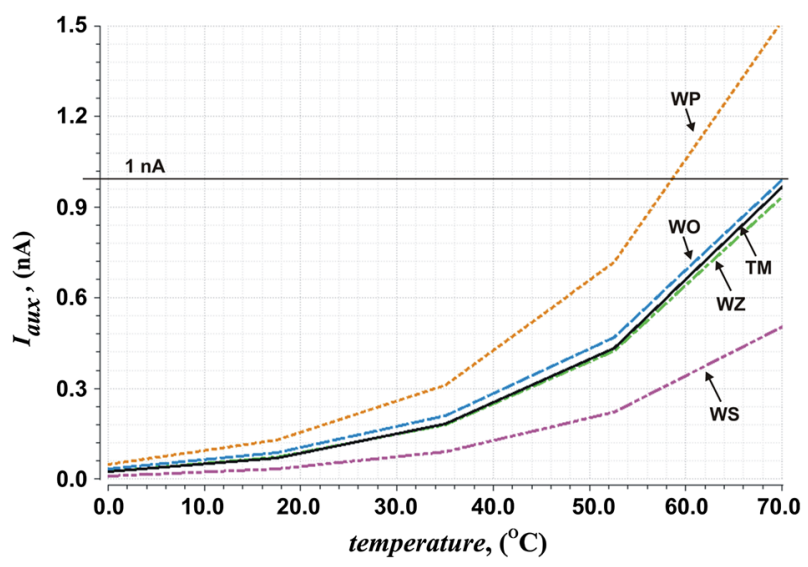

Fig. 10 The minimum $I_{\text {aux }}$ necessary to initiate the starter as a function of temperature and corners

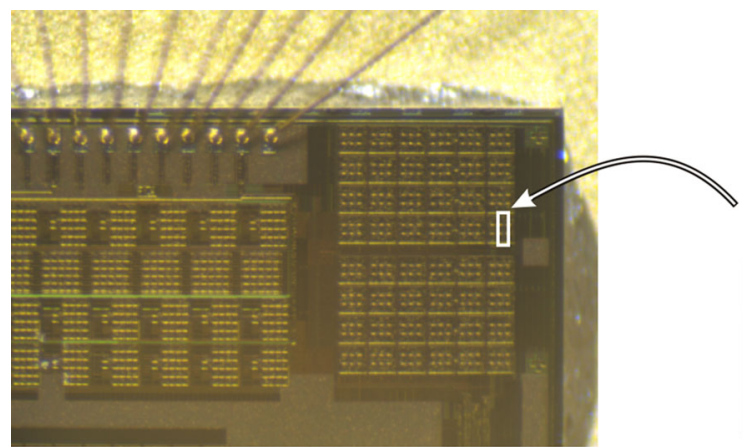

(a)

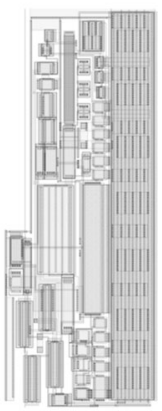

(b)

Fig. 11 a Micro-photograph of the chip portion containing the starter. b Design of the starter layout $(21 \mu \mathrm{m} \times$ $110.7 \mu \mathrm{m})$

current value allows the use of on-chip photovoltaic diodes or small external LED diode in photovoltaic mode.

\section{Measurement of a Prototype Starter}

The starter from Fig. 4 in the version with minimal starting energy was selected for fabrication in a standard AMS 180-nm CMOS technology. The designed starter's layout and the micro-photograph of the chip portion containing the starter are shown in Fig. 11. The complete starter without bonding pads occupies $2325 \mu \mathrm{m}^{2}$ of the chip area. The $\mathrm{L}_{1}, \mathrm{C}_{2}, \mathrm{C}_{5}$ and $\mathrm{R}_{\mathrm{L}}$ were implemented as external components with values $820 \mu \mathrm{H}, 120 \mathrm{pF}, 10 \mathrm{nF}$ and $1 \mathrm{M} \Omega$, respectively. In the test setup (Fig. 12), the main power source $V_{\mathrm{DD}}$ was a photodiode BPW20RF (manufactured by Vishay) shunted by the capacitor $\mathrm{C}_{\mathrm{D}}$ with $3.3 \mu \mathrm{F}$ value. The auxiliary current $I_{\text {aux }}$ was generated by a light-emitting diode (LED) working in photovoltaic mode. We used a small green 


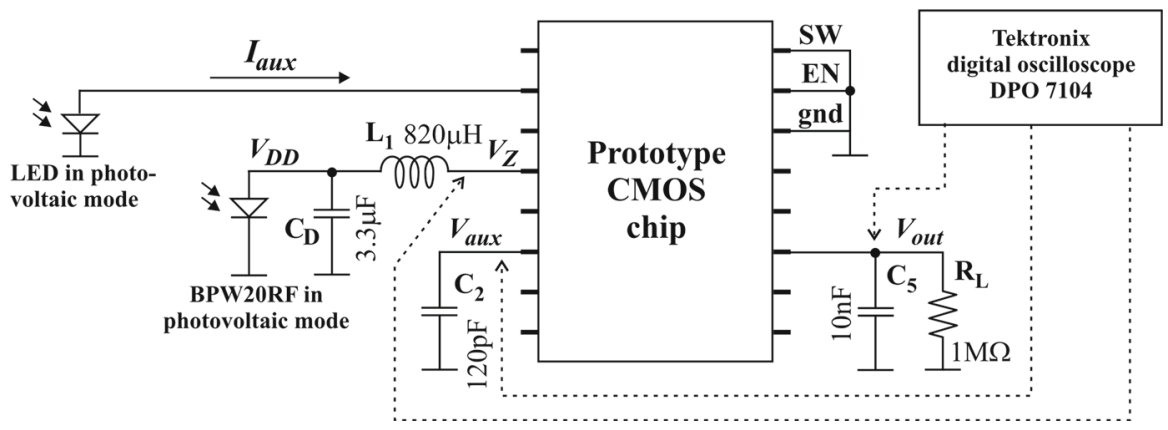

Fig. 12 The test setup

Table 4 Measured $V_{\text {out }}$ and $V_{\text {aux }}$ as a function of $V_{\mathrm{DD}}$

\begin{tabular}{lllllll}
\hline & $V_{\text {DD }}(\mathrm{mV})$ & 50 & 80 & 100 & 150 & 200 \\
\hline $0{ }^{\circ} \mathrm{C}$ & $V_{\text {out }}(\mathrm{V})$ & 1.61 & 2.32 & 2.43 & 2.60 & 2.69 \\
& $V_{\text {aux }}(\mathrm{V})$ & 1.42 & 2.25 & 2.35 & 2.53 & 2.61 \\
$27{ }^{\circ} \mathrm{C}$ & $V_{\text {out }}(\mathrm{V})$ & 1.39 & 2.24 & 2.35 & 2.55 & 2.62 \\
& $V_{\text {aux }}(\mathrm{V})$ & 1.13 & 1.92 & 2.05 & 2.21 & 2.35 \\
$50^{\circ} \mathrm{C}$ & $V_{\text {out }}(\mathrm{V})$ & 1.15 & 2.08 & 2.12 & 2.18 & 2.25 \\
& $V_{\text {aux }}(\mathrm{V})$ & 1.02 & 1.91 & 2.02 & 2.05 & 2.15 \\
\hline
\end{tabular}

LED with $1.1 \mathrm{~V}$ open circuit voltage and $1 \mathrm{nA}$ short-circuit current at 1 klux. Using the configuration in Fig. 12, the relation between $V_{\mathrm{DD}}, V_{\text {out }}$ and $V_{\text {aux }}$ was measured. The $V_{\mathrm{DD}}$ was changed by increasing illuminance of incident light. The results of measurements taken for $V_{\mathrm{DD}}$ changed from $50 \mathrm{mV}$ to $200 \mathrm{mV}$ are presented in Table 4. The value of the auxiliary current $I_{\text {aux }}$ supplying the starter ranges from $120 \mathrm{pA}$ at $0{ }^{\circ} \mathrm{C}$ to $0.8 \mathrm{nA}$ at $50^{\circ} \mathrm{C}$. The current measured at room temperature $\left(27^{\circ} \mathrm{C}\right)$ is $240 \mathrm{pA}$.

Figure 13 shows captured waveforms of $V_{\text {out }}, V_{\text {aux }}$ and $V_{Z}$ for $V_{\mathrm{DD}}=50 \mathrm{mV}$. It is seen that the first pulse of $V_{Z}$ charges $C_{2}$ to $V_{\text {aux }}>1.9 \mathrm{~V}$, which ensures correct operation of the relaxation oscillator. At the same time, as shown in Fig. 13b, the voltage $V_{\text {out }}$ is delayed and limited in amplitude to $400 \mathrm{mV}$. During the successive switching of $\mathrm{M}_{1}$, the $V_{\text {out }}$ increases gradually to the final value of $1.39 \mathrm{~V}$.

\section{Comparison}

Most of the starters described in the literature are designed to achieve the lowest possible start-up voltage, and therefore, comparison of the starter proposed in this paper is difficult. Two groups of the starters are compared: the starters using an auxiliary voltage source $[1,3,7]$ and the starter using a single low-voltage source shared with the boost converter [17]. A summary of the most important parameters of the selected starters is given in Table 5. The solution in [1] requires at least $600 \mathrm{mV}$ to start-up and consumes $1.1 \mu \mathrm{W}$ of quiescent power, which means $1.8 \mu \mathrm{A}$ inrush current. The starter [3] at the same voltage needs at least $2 \mu \mathrm{W}$, which results in $3.3 \mu \mathrm{A}$ inrush 


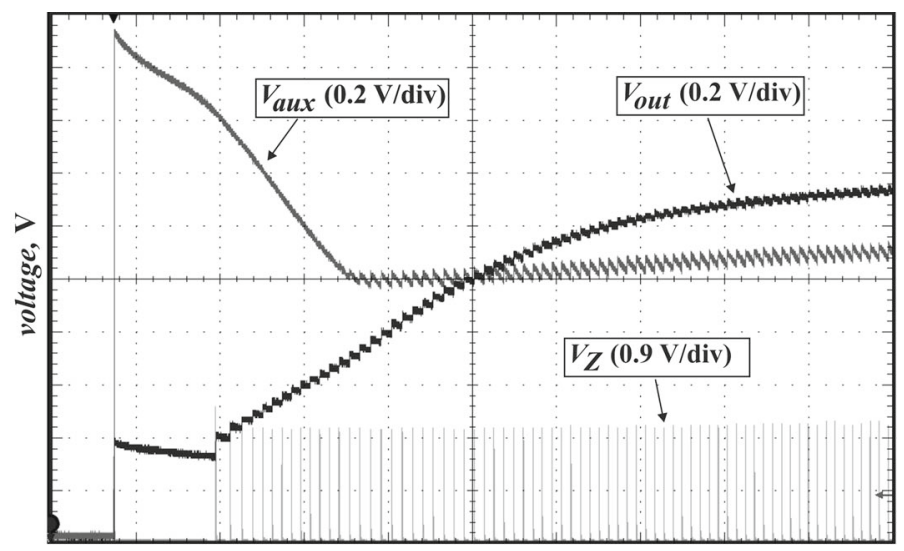

time, $1 \mathrm{~ms} / \mathrm{div}$

(a)

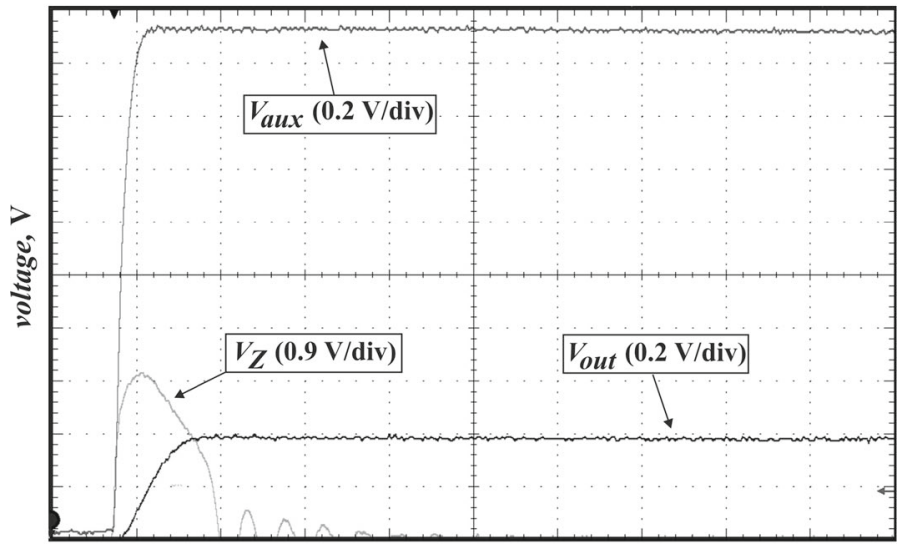

time, $20 \mu \mathrm{s} / \mathrm{div}$

(b)

Fig. 13 Oscilloscope measurements of waveforms: $V_{\text {out }}, V_{\text {aux }}$ and $V_{Z}$ : a start-up after applying $V_{\mathrm{DD}}=$ $50 \mathrm{mV}$, b enlarged initial part of $V_{\text {out }}, V_{\text {aux }}$ and $V_{Z}$ waveforms

current. The control circuit used in the starter [7] requires at least $1 \mathrm{~V}$ and consumes $160 \mathrm{nW}$ of power, and therefore, it requires $160 \mathrm{nA}$ of inrush current. The converter in [17] can start up by itself due to the application of a MOS transistor with a low threshold voltage. During the start-up period, $1.3 \mu \mathrm{W}$ of power is consumed at $35 \mathrm{mV}$ (37 $\mu \mathrm{A}$ inrush current). The proposed starter consumes auxiliary current in the range from $120 \mathrm{pA}\left(0^{\circ} \mathrm{C}\right)$ to $0.8 \mathrm{nA}\left(50^{\circ} \mathrm{C}\right)$ at the starting voltage in the range from $970 \mathrm{mV}$ to $850 \mathrm{mV}$, and therefore, the static power consumed varies from $0.117 \mathrm{nW}$ to 0.68 $\mathrm{nW}$. 
Table 5 Performance comparison of selected starters

\begin{tabular}{llllll}
\hline References & {$[1]$} & {$[3]$} & {$[7]$} & {$[17]$} & This work \\
\hline Start-up voltage, mV & 600 & 600 & 1000 & 35 & $820-946$ \\
Inrush current, nA & 1800 & 3300 & 160 & 37000 & $0.12-0.8$ \\
Quiescent power & $1.1 \mu \mathrm{W}$ & $2.0 \mu \mathrm{W}$ & $160 \mathrm{nW}$ & $1.3 \mu \mathrm{W}$ & $0.12-0.68 \mathrm{nW}$ \\
Start-up time, ms & $\mathrm{na}$ & $\mathrm{na}$ & $\mathrm{na}$ & $\mathrm{na}$ & $1.4-10$ \\
Switching frequency & $0.044-5 \mathrm{MHz}$ & $42-320 \mathrm{kHz}$ & $15 \mathrm{kHz}$ & $1-100 \mathrm{kHz}$ & $6.5-50 \mathrm{kHz}$ \\
Output voltage, $\mathrm{V}$ & 1 & 0.9 & 1.9 & 1 & $1-2.7$ \\
CMOS technology & $130 \mathrm{~nm}$ & $350 \mathrm{~nm}$ & $180 \mathrm{~nm}$ & $130 \mathrm{~nm}$ & $180 \mathrm{~nm}$ \\
\hline
\end{tabular}

\section{Conclusion}

In this paper, the starter able to generate a starting voltage in the range from 1 to $2.7 \mathrm{~V}$ at a supply voltage from 50 to $200 \mathrm{mV}$ is presented. The starter is designed for a low-voltage, micro-power boost DC-DC converter intended for powering CMOS image sensors. A special feature of the proposed starter is extremely low current, below $1 \mathrm{nA}$, supplying its controller. Due to this, the controller can be powered from a high-voltage $(1.3 \mathrm{~V})$ configuration of series-connected photovoltaic diodes available in a standard CMOS process [10]. Therefore, the proposed solution is suitable for all kinds of image sensors, e.g., imagers, vision chips [6,8] implemented in CMOS technologies. The very low current supplying the controller was achieved by using a simple relaxation oscillator biased by the leakage current of MOS transistors. The performed simulations have shown that despite the use of such a simple solution, the starter works correctly. It was demonstrated that the starter can be designed in such a way to operate properly under temperature changes in the range of $0-50{ }^{\circ} \mathrm{C}$ and process variation. The starter was verified using a prototype chip fabricated in $180-\mathrm{nm}$ CMOS technology. The starter output voltage measured at $0{ }^{\circ} \mathrm{C}, 27{ }^{\circ} \mathrm{C}$ and $50{ }^{\circ} \mathrm{C}$ is in the range of $1.1-2.7 \mathrm{~V}$, whereas the controller supply current is within the range of $0.12-0.8 \mathrm{nA}$.

Acknowledgements This work was supported in part by the National Science Centre of Poland under Grants 2011/03/B/ST7/03547 and 2016/23/B/ST7/03733.

Open Access This article is distributed under the terms of the Creative Commons Attribution 4.0 International License (http://creativecommons.org/licenses/by/4.0/), which permits unrestricted use, distribution, and reproduction in any medium, provided you give appropriate credit to the original author(s) and the source, provide a link to the Creative Commons license, and indicate if changes were made.

\section{References}

1. E. Carlson, K. Strunz, B. Otis, A $20 \mathrm{mV}$ input boost converter with efficient digital control for thermoelectric energy harvesting. IEEE J. Solid-State Circuits 45, 741-750 (2010). https://doi.org/10.1109/ JSSC.2010.2042251

2. J. Damaschke, Design of a low-input-voltage converter for thermoelectric generator. IEEE Trans. Ind. Appl. 33, 1203-1207 (1997). https://doi.org/10.1109/28.633797 
3. I. Doms, P. Merken, R. Mertens, C. Van Hoof, Integrated capacitive power-management circuit for thermal harvesters with output power 10 to $1000 \mu \mathrm{W}$, in Digest of Technical Papers IEEE International Solid-State Circuits Conference (ISSCC) (2009), pp. 300-301. https://doi.org/10.1109/isscc. 2009.4977427

4. H. Fuketa, S. O'uchi, T. Matsukawa, Fully integrated, 100-mV minimum input voltage converter with gate-boosted charge pump kick-started by LC oscillator for energy harvesting. IEEE Trans. Circuits Syst. II Express Briefs 64, 392-396 (2017). https://doi.org/10.1109/tcsii.2016.2573382

5. J.-P. Im, S.-W. Wang, S.-T. Ryu, G.-H. Cho, A $40 \mathrm{mV}$ transformer-reuse self-startup boost converter with MPPT control for thermoelectric energy harvesting. IEEE J. Solid-State Circuits 47, 3055-3067 (2012). https://doi.org/10.1109/JSSC.2012.2225734

6. W. Jendernalik, G. Blakiewicz, J. Jakusz, S. Szczepański, An analog sub-miliwatt CMOS image sensor with pixel-level convolution processing. IEEE Trans. Circuits Syst. I Reg. Pap. 60, 279-289 (2013). https://doi.org/10.1109/tcsi.2012.2215803

7. J. Katic, S. Rodriguez, A. Rusu, A dual-output thermoelectric energy harvesting interface with $86.6 \%$ peak efficiency at $30 \mu \mathrm{W}$ and total control power of $160 \mathrm{nW}$. IEEE J. Solid-State Circuits 51, 189-204 (2016). https://doi.org/10.1109/jssc.2016.2561959

8. M. Kłosowski, W. Jendernalik, J. Jakusz, G. Blakiewicz, S. Szczepański, A CMOS pixel with embedded ADC, digital CDS and gain correction capability for massively parallel imaging array. IEEE Trans. Circuits Syst. I Reg. Pap. 64, 38-49 (2017). https://doi.org/10.1109/tcsi.2016.2610524

9. K.R. Laker, W.M.C. Sansen, Design of Analog Integrated Circuits and Systems (McGraw-Hill, New York, 1994)

10. M.K. Law, A. Bermak, High-voltage generation with stacked photodiodes in standard CMOS process. IEEE Electron Device Lett. 31, 1425-1427 (2010). https://doi.org/10.1109/LED.2010.2075910

11. V. Leonov, T. Torfs, P. Fiorini, C. Van Hoof, Thermoelectric converters of human warmth for selfpowered wireless sensor nodes. IEEE Sens. J. 5, 650-657 (2007). https://doi.org/10.1109/JSEN.2007. 894917

12. B. Lim, J. Seo, S. Lee, A Colpitts oscillator-based self-starting boost converter for thermoelectric energy harvesting with $40-\mathrm{mV}$ startup voltage and $75 \%$ maximum efficiency. IEEE J. Solid-State Circuits $\mathbf{5 3}$, 3293-3302 (2018). https://doi.org/10.1109/JSSC.2018.2863951

13. L. Liu, J. Mu, N. Ma, W. Tu, Z. Zhu, Y. Yang, An ultra-low-power integrated RF energy harvesting system in 65-nm CMOS process. Circuits Syst. Signal Process. 35, 421-441 (2016). https://doi.org/ 10.1007/s00034-015-0092-7

14. R.D. Prabha, G.A. Rincon-Mora, CMOS photovoltaic-cell layout configurations for harvesting microsystems, in Proceedings of International Midwest Symposium on Circuits and Systems (MWSCAS) (2013), pp. 368-371. https://doi.org/10.1109/mwscas.2013.6674662

15. Y. Ramadass, A. Chandrakasan, An efficient piezoelectric energy harvesting interface circuit using a bias-flip rectifier and shared inductor. IEEE J. Solid-State Circuits 45, 189-204 (2010). https://doi.org/ 10.1109/JSSC.2009.2034442

16. Y. Ramadass, A. Chandrakasan, A battery-less thermoelectric energy harvesting interface circuit with $35 \mathrm{mV}$ startup voltage. IEEE J. Solid-State Circuits 46, 333-341 (2011). https://doi.org/10.1109/JSSC. 2010.2074090

17. Y.-K. The, P.K.T. Mok, Design of transformer-based boost converter for high internal resistance energy harvesting sources with $21 \mathrm{mV}$ self-startup voltage and $74 \%$ power efficiency. IEEE J. Solid-State Circuits 49, 2694-2704 (2014). https://doi.org/10.1109/JSSC.2014.2354645

18. P.-S. Weng, H.-Y. Tang, P.-C. Ku, L.-H. Lu, $50 \mathrm{mV}$-input batteryless boost converter for thermal energy harvesting. IEEE J. Solid-State Circuits 48, 1031-1041 (2013). https://doi.org/10.1109/JSSC. 2013.2237998

19. Y. Yang, X.-J. Wei, J. Liu, Suitability of a thermoelectric power generator for implantable medical electronic devices. J. Phys. D Appl. Phys. 40, 5790-5800 (2007). https://doi.org/10.1088/0022-3727/ 40/18/042

20. Y. Zhang, F. Zhang, Y. Shakhsheer, J.D. Silver, A. Klinefelter, M. Nagaraju, J. Boley, J. Pandey, A. Shrivastava, E.J. Carlson, A. Wood, B.H. Calhoun, B.P. Otis, A batteryless $19 \mu \mathrm{W}$ MICS/ISM-band energy harvesting body sensor node SoC for ExG applications. IEEE J. Solid-State Circuits 48, 199-213 (2013). https://doi.org/10.1109/JSSC.2012.2221217

Publisher's Note Springer Nature remains neutral with regard to jurisdictional claims in published maps and institutional affiliations. 